\title{
Association between Health Problems and Turnover Intention in Shift Work Nurses: Health Problem Clustering
}

\author{
Jison Ki ${ }^{1}$, Jaegeum Ryu ${ }^{2}$, Jihyun Baek ${ }^{2}$, Iksoo Huh ${ }^{1,2}$ and Smi Choi-Kwon ${ }^{1,2, *}$ \\ 1 College of Nursing, Seoul National University, 103, Daehak-ro, Jongno-gu, Seoul 03080, Korea; \\ candy8@snu.ac.kr (J.K.); huhixoo@gmail.com (I.H.) \\ 2 The Research Institute of Nursing Science, Seoul National University, 103, Daehak-ro, Jongno-gu, \\ Seoul 03080, Korea; jgryu21@gmail.com (J.R.); jihyunoctober@gmail.com (J.B.) \\ * Correspondence: smi@snu.ac.kr; Tel.: +82-2-740-8830
}

Received: 1 June 2020; Accepted: 21 June 2020; Published: 24 June 2020

\begin{abstract}
Shift work nurses experience multiple health problems due to irregular shifts and heavy job demands. However, the comorbidity patterns of nurses' health problems and the association between health problems and turnover intention have rarely been studied. This study aimed to identify and cluster shift work nurses' health problems and to reveal the associations between health problems and turnover intention. In this cross-sectional study, we analyzed data from 500 nurses who worked at two tertiary hospitals in Seoul, South Korea. Data, including turnover intention and nine types of health issues, were collected between March 2018 and April 2019. Hierarchical clustering and multiple ordinal logistic regressions were used for the data analysis. Among the participants, $22.2 \%$ expressed turnover intention and the mean number of health problems was 4.5 (range $0-9$ ). Using multiple ordinal logistic regressions analysis, it was shown that sleep disturbance, depression, fatigue, a gastrointestinal disorder, and leg or foot discomfort as a single health problem significantly increased turnover intention. After clustering the health problems, four clusters were identified and only the neuropsychological cluster-sleep disturbance, fatigue, and depression-significantly increased turnover intention. We propose that health problems within the neuropsychological cluster must receive close attention and be addressed simultaneously to decrease nurse's turnover intentions.
\end{abstract}

Keywords: nurses; turnover intention; hierarchical clustering; fatigue; sleep

\section{Introduction}

Nurses often work irregular shifts and bear high physical and psychological job demands that may, in turn, jeopardize their health status. Specifically, shift work may cause a variety of physical and mental health problems [1]. The deterioration of nurses' health status could not only lead to a decline in their quality of life but could also affect the quality of care provided by them [2]. In addition, health problems may affect nurses' turnover, which is a serious issue worldwide [3]. The high turnover rate of nurses has led to an increase in both direct and indirect costs in the health system and could further protract the shortage of nurses that has lasted for the past several years [4]. A recent survey of Korean nurses reported that about $10 \%$ of shift work nurses cited health problems as their main reason for resigning [5].

Prior studies also show that nurses complained of two or more health problems simultaneously, which may be interrelated [2,6-8]. Musculoskeletal pain in nurses has been reported in many studies $[9,10]$, and poor dietary habits due to irregular shift work were reported to cause gastrointestinal disorders [11,12]. Sleep disturbance, which is most frequently reported in studies of shift nurses, could lead to mood disorders, such as depression, both of which lead to chronic fatigue [13-15]. 
Although nurses experience various health problems, there is relatively little research on the relationships between complex health problems in nurses [2]. Moreover, few studies have investigated the relationship between concomitant health problems and turnover intention.

Because the burden may vary depending on the number and the kind of health problems shift work nurses have [16], it may be important to identify specific comorbidity patterns of nurses' health problems through clustering and determine which clusters most affect turnover intention, where a cluster-that is, a comorbid pattern of health problems - can be defined as a group of concurrent or related health problems that can be distinguished from other clusters [17].

Therefore, the purpose of this study was to first characterize shift work nurses' health problems. We then determined the pattern of symptom modalities by clustering the health problems through the hierarchical clustering method. Lastly, we identified the impact of health problem clusters on turnover intention.

\section{Materials and Methods}

\subsection{Study Design and Participants}

This cross-sectional study was part of the Shift Work Nurses' Health and Turnover (SWNHT) study, which is a prospective cohort study designed to investigate the longitudinal relationships between shift work nurses' health and turnover. It was supported by the National Research Foundation of Korea (NRF) grant funded by the Korea Ministry of Science and Information and Communications Technologies and approved by the Institutional Review Board (IRB) at two tertiary hospitals in Seoul, South Korea. Data collection was performed from March 2018 until April 2020. In the SWNHT study, we recruited 594 female nurses (294 novice nurses who had no exposure to rotating shift work, and 300 nurses with exposure to 8-hour rotating work, including night shifts, for at least 1 month) (Figure 1). Because health problems can vary according to sex $[18,19]$ and the SWNHT study included a survey of nurses' menstrual and gynecological symptoms, the SWNHT study was limited to female nurses. Data were collected three times for novice nurses: before exposure to shift work (novice registered nurse (NRN) T0, $n=294$ ), after six months of work (NRN T1, $n=204$ ), and 12 months after T1 (NRN T2, $n=204$ ). For experienced registered nurses, data were collected twice: baseline (experienced registered nurse (ERN) T1, $n=300$ ) and 12 months after T1 (ERN T2, $n=269$; see details in Section 2.2 Data Collection).

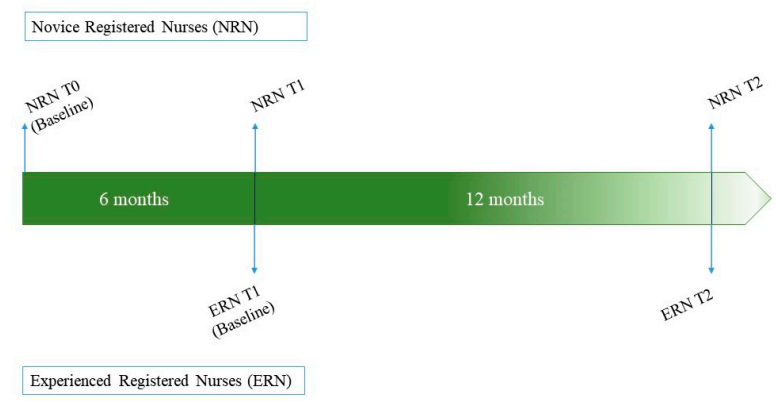

Figure 1. Schematic overview of the Shift Work Nurses' Health and Turnover (SWNHT) study.

In this study, we used data collected from October 2018 to January 2019 (NRN T1, $n=204$ ) and from March 2018 to May 2018 (ERN T1, $n=300$ ) to analyze the association between health problems and turnover intention among shift work nurses. In this analysis, we defined shift work as a combination of day, evening, and night shifts; therefore, we excluded four nurses, including three nurses who worked only daytime hours and one nurse who worked from midday to 8 p.m.

\subsection{Data Collection}

The primary purpose of the SWNHT study was to investigate health problems, presenteeism, and turnover intention in shift work nurses. To enroll novice nurses without shift work experience, 
we distributed and collected survey envelope packages that included survey instructions, consent forms, and a questionnaire on the third day of their work orientation before ward placement. To enroll experienced shift work nurses, we attached a recruitment notice to the ward bulletin boards, and nurses who wished to participate in the study voluntarily contacted the research team. We maximized voluntary participation by protecting confidentiality, ensuring anonymity, and no hospital-associated researchers took part in the data collection process. We collected the follow-up data through an online survey program; their response rates were 69.4\% (NRN T1, NRN T2) and 89.7\% (ERN T1). The SWNHT study questionnaire included questions regarding general and job-related characteristics, health-related variables (e.g., dietary habits, menstrual symptoms, exposure to blood and body fluid, sleep, fatigue, depression, physical activity, etc.), occupational stress, presenteeism, and turnover intention. To objectively verify the sleep scale data, we also obtained actigraphy data from the subjects who consented to wear the actigraphy.

\subsection{Measurements}

\subsubsection{Demographic and Job-Related Characteristics}

The examined demographic characteristics included age (years), education (bachelor's degree or lower/master's degree or higher), marital status (single/married), having children (yes/no), and body mass index $\left(\mathrm{kg} / \mathrm{m}^{2}\right)$. The examined job-related characteristics included work unit (general ward, intensive care unit, delivery room, and emergency room), months of shift work experience, and the average number of night shifts per month.

\subsubsection{Turnover Intention}

We measured turnover intention since it is the most predictive measure of actual turnover [20]. In a longitudinal study in Europe, nurses who had turnover intentions were more likely to leave their jobs [21]. In this study, the subjects were asked to choose one of four options (strongly agree, agree, disagree, or strongly disagree) to answer the question: "I plan on staying for the next year" [22].

\subsubsection{Health Problems}

The nine health problems in this study were selected by two professors at a nursing college and two nurses in a research team, and were based on reviews of the literature about shift work nurses' health problems $[10,18,23-27]$. These were (1) upper musculoskeletal pain (including neck, shoulder, and back pain), (2) leg or foot discomfort, (3) sleep disturbance, (4) fatigue, (5) depression, (6) menstrual disorders (including dysmenorrhea and menopause symptoms), (7) gynecological disorders (including disease of the uterus or ovary), (8) headaches (including migraine, dizziness, and chronic headaches), and (9) gastrointestinal disorders (including gastric ulcer, diarrhea, constipation, and stomachache).

Among the nine health problem categories, sleep disturbance, fatigue, and depression were measured using the instruments described below. For the other six health problem categories, the subjects were asked to indicate the health problems they experienced during the last month with "yes" or "no."

\section{Sleep Disturbance}

To assess the quality of sleep, we used the Korean version of the Insomnia Severity Index (ISI), which was developed by Morin and translated by the Korean Sleep Research Society. The insomnia severity scale consists of seven questions related to sleep disorders measured on a 5-point scale (0-4 points) for each item. The score ranges from 0 to 28; higher scores indicate a lower quality of sleep. A score above 10 indicates sleep disturbance [28]. The Cronbach's alpha value of the Korean version of ISI was 0.928 in our study.

\section{Fatigue}

Fatigue was measured using the Fatigue Severity Scale (FSS). The FSS consists of nine questions about the degree of fatigue during the past week and is scored from 1 (strongly disagree) to 7 (strongly 
agree). A higher average score indicates higher fatigue. The criterion for fatigue is more than four points on average [29]. The Cronbach's alpha value of the FSS was 0.917 in our study.

\section{Depression}

We measured depression using the shortened Center for Epidemiological Studies Depression Scale (CES-D). The shortened CES-D consists of 10 questions about depressive feelings and thoughts during the past week and is scored from 0 (less than 1 day) to 3 (about 5-7 days). Higher total scores indicate more depressive symptoms. A total score of 10 or above indicates depression [30]. The Cronbach's alpha value of the shortened CES-D was 0.877 in our study.

\subsection{Statistical Analysis}

All analyses were performed using SAS version 9.4 (SAS Institute Inc., Cary, NC, USA) and R Project for Statistical Computing software version 3.4.4 (CRAN, Soule, Korea). We confirmed that there were no missing data. The descriptive statistics (frequency, percentage, mean, and standard deviation) for the demographic characteristics were analyzed. Pearson's chi-squared test, Fisher's exact test, and an analysis of variance were used to identify general characteristics associated with turnover intention. Hierarchical clustering was used to group the health problems reported by participants. Hierarchical clustering is a statistical method for grouping objects or variables according to the similarity between clusters using a bottom-up approach. In the field of nursing, this technique has been used mainly for symptom clustering of cancer patients; however, it has recently become more widely used in various studies [31]. The method used for measuring the distance between variables was the squared Euclidean distance and the linkage method used for measuring the distance between clusters was the average linkage. The number of final clusters is usually determined by the researchers by taking into account clinical suitability [32]. Multiple ordinal logistic regressions that included covariates, such as education, marital status, having children, body mass index $\left(\mathrm{kg} / \mathrm{m}^{2}\right)$, work unit, months of shift work experience, and the number of night shifts per month, was used to investigate the association of single health problems and clusters of health problems with turnover intention. The four categories of "strongly agree," "agree," "disagree," and "strongly disagree" used for the turnover intention variable satisfied the proportional odds assumption at $p>0.050$ with the covariates and variables of interest.

\subsection{Ethical Consideration}

This study was approved by the Institutional Review Board (IRB) at Seoul National University Hospital (IRB No. H-1712-094-907) and the Samsung Medical center (IRB No. 2017-12-075-002). After agreeing to participate in the study, all nurse participants signed a consent form and completed the baseline questionnaire.

\section{Results}

\subsection{Demographic and Job-Related Characteristics}

The participants were 500 female nurses working shifts, including night shifts. The nurses' mean age was 26.7 years (standard deviation $(\mathrm{SD})=4.20$ ), and $19.8 \%$ were over 30 years old. There were no differences in demographic and job-related characteristics between the participants in the two tertiary hospitals. Most nurses were single $(88.2 \%)$ and had no children $(94.0 \%)$. The average body mass index (BMI) was $20.19 \mathrm{~kg} / \mathrm{m}^{2} ; 22.8 \%$ of the subjects were underweight and only one subject was obese. The shift work length was 35 months on average, which was highly correlated with age $(r=0.92$, $p<0.001)$. Therefore, we excluded age from the covariates of the multiple ordinal logistic regressions (Table 1). 
Table 1. Demographic and job-related characteristics by turnover intention $(n=500)$.

\begin{tabular}{|c|c|c|c|c|c|c|c|c|}
\hline \multirow{2}{*}{ Variables } & \multirow{2}{*}{ Categories } & \multirow{2}{*}{$\begin{array}{c}\text { Total } \\
(n=500,100.0 \%) \\
n(\%) \text { or } \mathrm{M} \pm \mathrm{SD}\end{array}$} & \multirow{2}{*}{$\begin{array}{c}\text { Strong Intent to } \\
\text { Stay } \\
(n=53,10.5 \%) \\
n(\%) \text { or } \mathrm{M} \pm \mathrm{SD}\end{array}$} & \multirow{2}{*}{$\begin{array}{c}\text { Intent to Stay } \\
(n=336,67.2 \%) \\
n(\%) \text { or } \mathrm{M} \pm \mathrm{SD}\end{array}$} & \multirow{2}{*}{$\begin{array}{c}\text { Intent to Leave } \\
\begin{array}{c}(n=99,19.9 \%) \\
n(\%) \text { or } M \pm S D\end{array}\end{array}$} & \multirow{2}{*}{$\begin{array}{l}\text { Strong Intent to Leave } \\
\begin{array}{c}(n=12,2.4 \%) \\
n(\%) \text { or } \mathrm{M} \pm \mathrm{SD}\end{array}\end{array}$} & \multirow{2}{*}{$\chi^{2}$ or $\mathrm{F}$} & \multirow{2}{*}{$p$} \\
\hline & & & & & & & & \\
\hline Age (years) & & $26.72 \pm 4.20$ & $28.77 \pm 5.68$ & $26.29 \pm 3.87$ & $27.08 \pm 4.31$ & $26.58 \pm 2.35$ & 5.70 & $0.001 *$ \\
\hline \multirow[t]{2}{*}{ Education } & $\leq \mathrm{BSN}$ & 459 (91.8) & $48(90.6)$ & $310(92.3)$ & $89(89.9)$ & $12(100.0)$ & 1.74 & 0.626 \\
\hline & $\geq \mathrm{MSN}$ & $41(8.2)$ & $5(9.4)$ & $26(7.7)$ & $10(10.1)$ & $0(0.0)$ & & \\
\hline \multirow[t]{2}{*}{ Marital Status } & Single & $441(88.2)$ & $42(79.3)$ & $303(90.2)$ & $85(85.9)$ & $11(91.7)$ & 6.00 & 0.108 \\
\hline & Married & $59(11.8)$ & $11(20.7)$ & $33(9.8)$ & $14(14.1)$ & $1(8.3)$ & & \\
\hline \multirow[t]{2}{*}{$\begin{array}{l}\text { Having } \\
\text { Children }\end{array}$} & Yes & $30(6.0)$ & $8(15.1)$ & $15(4.5)$ & $7(7.1)$ & $0(0.0)$ & 10.14 & 0.030 * \\
\hline & No & $470(94.0)$ & 45 (84.9) & $321(95.5)$ & $92(92.9)$ & $12(100.0)$ & & \\
\hline \multirow{4}{*}{$\begin{array}{l}\text { Body Mass } \\
\text { Index }\left(\mathrm{kg} / \mathrm{m}^{2}\right) \\
\text { Work Unit }\end{array}$} & & $20.19 \pm 2.24$ & $20.96 \pm 2.36$ & $20.19 \pm 2.19$ & $19.92 \pm 2.34$ & $18.77 \pm 1.22$ & 4.24 & 0.006 * \\
\hline & Ward & $366(73.2)$ & $41(77.4)$ & $239(71.1)$ & $76(76.8)$ & $10(83.3)$ & 4.61 & 0.673 \\
\hline & $\mathrm{ICU}$ & $109(21.8)$ & $8(15.1)$ & $79(23.5)$ & $20(20.2)$ & $2(16.7)$ & & \\
\hline & DR, ER & $25(5.0)$ & $4(7.5)$ & $18(5.4)$ & $3(3.0)$ & $0(0.0)$ & & \\
\hline \multicolumn{2}{|c|}{$\begin{array}{l}\text { Shift Work Experience } \\
\text { (months) }\end{array}$} & $34.93 \pm 42.94$ & $58.66 \pm 59.97$ & $30.84 \pm 40.01$ & $37.03 \pm 39.38$ & $27.58 \pm 27.80$ & 6.83 & $<0.001$ * \\
\hline \multicolumn{2}{|c|}{$\begin{array}{l}\text { Average Number of Nights } \\
\text { Per Month (days) }\end{array}$} & $6.00 \pm 1.26$ & $5.62 \pm 1.48$ & $5.98 \pm 1.37$ & $6.06 \pm 1.16$ & $6.13 \pm 0.78$ & 1.45 & 0.228 \\
\hline
\end{tabular}

BSN-Bachelor of Science in Nursing, MSN-Master of Science in Nursing, ICU-Intensive Care Unit, DR-delivery room, ER-emergency room; $p<0.05$. 
One hundred and eleven nurses (22.2\%) had a turnover intention and 12 nurses $(2.4 \%)$ strongly intended to leave. The turnover intention was statistically higher in subjects who were younger $(\mathrm{F}=5.70, p=0.001)$, had no children $\left(\chi^{2}=10.14, p=0.030\right)$, had a lower BMI $(\mathrm{F}=4.24, p=0.006)$, and had shorter periods of shift work $(\mathrm{F}=6.83, p<0.001)$.

\subsection{Prevalence and Association between Single Health Problems and Turnover Intention}

The mean number of health problems was 4.5 (range $0-9)$, with $95.2 \%(n=476)$ of participants having more than two health problems. The most frequently reported health problem was upper musculoskeletal pain $(82.4 \%)$, followed by leg or foot discomfort $(67.8 \%)$, fatigue $(65.0 \%)$, and sleep disturbance $(62.4 \%)$. The associations between single health problems and turnover intention using multiple ordinal logistic regressions are provided in Table 2. Fatigue (odds ratio $(\mathrm{OR})=3.4$, $95 \%$ confidence interval $(\mathrm{CI})=2.21-5.24)$, depression $(\mathrm{OR}=1.79,95 \% \mathrm{CI}=1.22-2.62)$, leg or foot discomfort $(\mathrm{OR}=1.69,95 \% \mathrm{CI}=1.12-2.56)$, sleep disturbance $(\mathrm{OR}=1.61,95 \% \mathrm{CI}=1.10-2.37)$, and a gastrointestinal disorder $(\mathrm{OR}=1.51,95 \% \mathrm{CI}=1.03-2.19)$ were significantly related to turnover intention.

Table 2. Association between single health problems and turnover intention using a multiple ordinal logistic regression.

\begin{tabular}{|c|c|c|c|c|}
\hline \multirow{2}{*}{ Variables } & Total & \multirow{2}{*}{$\begin{array}{l}\text { Adjusted }{ }^{1} \\
\text { Odds Ratio }\end{array}$} & \multirow{2}{*}{$95 \%$ CI } & \multirow{2}{*}{$p$} \\
\hline & $\begin{array}{c}(n=500,100.0 \%) \\
n(\%)\end{array}$ & & & \\
\hline Upper Musculoskeletal Pain & $412(82.4)$ & 1.07 & $0.65-1.74$ & 0.775 \\
\hline Leg or Foot Discomfort & $339(67.8)$ & 1.69 & $1.12-2.56$ & $0.012 *$ \\
\hline Sleep Disturbance & $312(62.4)$ & 1.61 & $1.10-2.37$ & $0.013 *$ \\
\hline Fatigue & $325(65.0)$ & 3.4 & $2.21-5.24$ & $<0.001 *$ \\
\hline Depression & $207(41.4)$ & 1.79 & $1.22-2.62$ & $0.002 *$ \\
\hline Menstrual Disorder & $194(38.8)$ & 1.26 & $0.86-1.85$ & 0.229 \\
\hline Gynecological Disorder & $36(7.2)$ & 0.98 & $0.47-2.01$ & 0.959 \\
\hline Headache & $195(39.0)$ & 1.2 & $0.82-1.75$ & 0.343 \\
\hline Gastrointestinal Disorder & $222(44.4)$ & 1.51 & $1.03-2.19$ & $0.031 *$ \\
\hline
\end{tabular}

\footnotetext{
${ }^{1}$ Adjusted for education, marital status, having children, body mass index $\left(\mathrm{kg} / \mathrm{m}^{2}\right)$, work unit, shift work experience
} (months), and the number of nights per month (days) in multiple ordinal logistic regression model; ${ }^{*} p<0.05$.

\subsection{Hierarchical Clustering of Health Problems}

Based on the hierarchical clustering analysis, four clusters were identified (Figure 2): the pain cluster (upper musculoskeletal pain and leg or foot discomfort), the neuropsychological cluster (depression, sleep disturbance, and fatigue), the gynecological cluster (menstrual disorder and gynecological disorder), and the gastrointestinal cluster (headache and gastrointestinal disorder).

\subsection{Prevalence and Association between Clusters of Health Problems and Turnover Intention}

As a result of our multiple ordinal logistic regression analyses, only the neuropsychological cluster (depression, sleep disturbance, and fatigue) was found to be significantly related to turnover intention. In the neuropsychological cluster, if the participant had only one health problem, it did not relate to turnover intention. If the participant experienced two ( $\mathrm{OR}=3.35,95 \% \mathrm{CI}=1.90-5.92)$ or three $(\mathrm{OR}=5.73,95 \% \mathrm{CI}=3.17-10.33)$ health problems in the cluster simultaneously, the odds ratio of the turnover intention increased linearly, which was statistically significant $(\mathrm{F}=5.84, p<0.001$; Table 3$)$. 


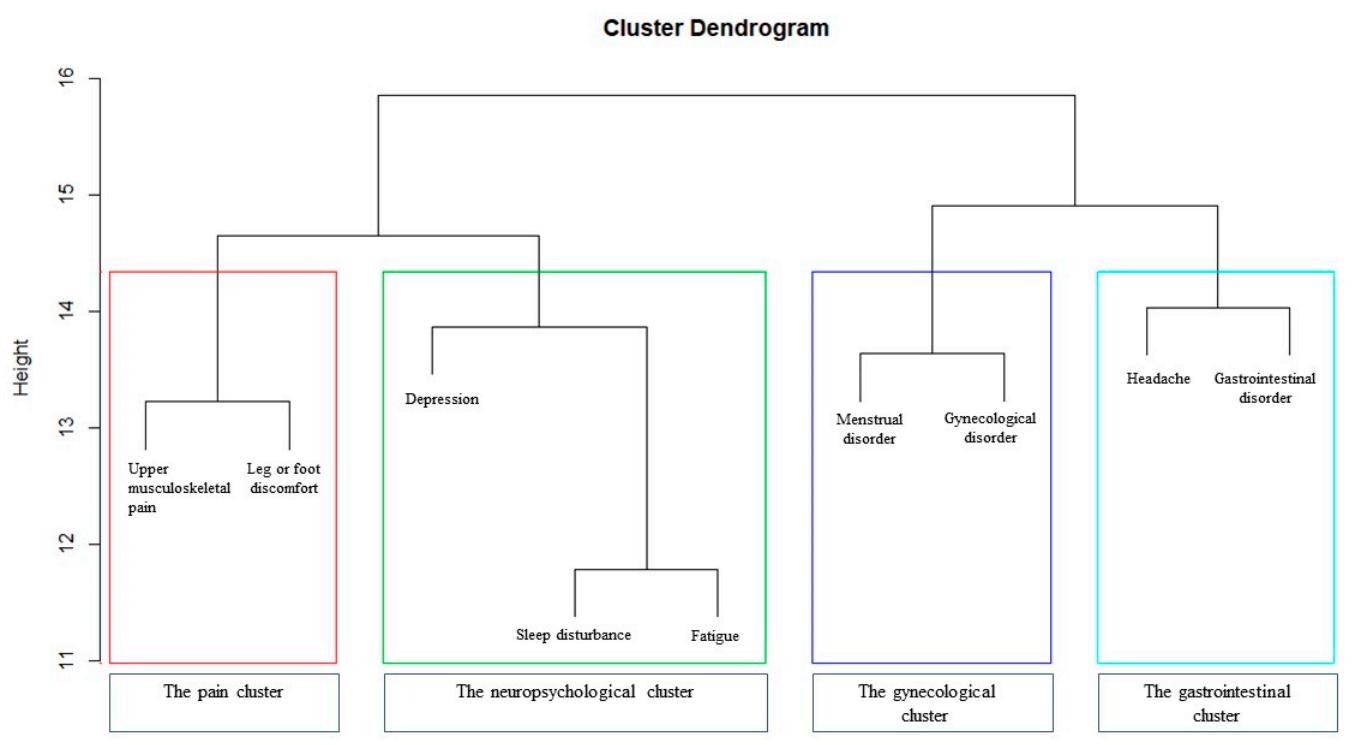

Figure 2. Dendrogram of the health problem clusters.

Table 3. Association between clusters of health problems and turnover intention using multiple ordinal logistic regressions.

\begin{tabular}{|c|c|c|c|c|c|c|}
\hline \multirow{2}{*}{ Cluster } & \multicolumn{3}{|c|}{ Health Problem } & \multicolumn{3}{|c|}{ Adjusted $^{1}$} \\
\hline & Contents & Number & $n(\%)$ & Odds Ratio & $95 \% \mathrm{CI}$ & $p$ \\
\hline \multirow{4}{*}{ Pain Cluster } & Upper & 0 & $37(7.4)$ & 1.00 & & \\
\hline & musculoskeletal pain & 1 & $175(35.0)$ & 0.57 & $0.27-1.23$ & 0.155 \\
\hline & + Leg or foot & 2 & $288(57.6)$ & 1.11 & $0.54-2.30$ & 0.763 \\
\hline & discomfort & 0 & $99(19.8)$ & 1.00 & & \\
\hline \multirow{3}{*}{$\begin{array}{l}\text { Neuropsychological } \\
\text { Cluster }\end{array}$} & Sleep disturbance + & 1 & $97(19.4)$ & 1.59 & $0.85-2.97$ & 0.141 \\
\hline & Fatigue + Depression & 2 & $165(33.0)$ & 3.35 & $1.90-5.92$ & $<0.001$ * \\
\hline & & 3 & $139(27.8)$ & 5.73 & $3.17-10.33$ & $<0.001 *$ \\
\hline \multirow{3}{*}{$\begin{array}{l}\text { Gynecological } \\
\text { Cluster }\end{array}$} & Menstrual disorder + & 0 & $292(58.4)$ & 1.00 & & \\
\hline & Gynecological & 1 & $186(37.2)$ & 1.22 & $0.83-1.81$ & 0.298 \\
\hline & disorder & 2 & $22(4.4)$ & 1.21 & $0.48-3.05$ & 0.676 \\
\hline \multirow{3}{*}{$\begin{array}{l}\text { Gastrointestinal } \\
\text { Cluster }\end{array}$} & Headache + & 0 & $193(38.6)$ & 1.00 & & \\
\hline & Gastrointestinal & 1 & $197(39.4)$ & 1.43 & $0.94-2.19$ & 0.092 \\
\hline & disorder & 2 & $110(22.0)$ & 1.60 & $0.98-2.64$ & 0.060 \\
\hline
\end{tabular}

${ }^{1}$ Adjusted for education, marital status, having children, body mass index $\left(\mathrm{kg} / \mathrm{m}^{2}\right)$, work unit, shift work experience (months), and the number of nights per month (days) in multiple ordinal logistic regression model; ${ }^{*}<0.05$.

\section{Discussion}

We investigated the prevalence of shift work nurses' health problems and characterized the patterns of symptom modalities by clustering health problems. We then investigated the association of single health problems and clusters of health problems with turnover intentions. We found that most shift work nurses experienced multiple health problems at the same time. We also found that having more than two health problems in the neuropsychological cluster was significantly related to turnover intention. This study was the first to attempt the clustering of nurses' health problems and explore the relationship between the clusters and turnover intention in shift work nurses.

We found that $22.2 \%$ of nurses had turnover intention. In previous studies, turnover intention varied from $4 \%$ to $54 \%$ [33-35]. The first reason for the difference in turnover intention between existing studies and our study could have been the different measurement tools used in each study. While our study asked about future plans regarding turnover, such as "I plan on staying for the next year," other studies asked how often they thought about turnover in the past [36,37]. Some studies measured turnover intention with various questions, such as whether they were seeking another job or whether they thought about leaving the nursing profession forever $[33,38]$. The second reason 
that turnover intention in our study was higher than in previous studies may be due to different hospital environments. The hospitals where our study was performed were tertiary hospitals in Seoul, which had a higher patient severity and higher nurse labor intensity than other hospitals in Korea. Third, we measured turnover intention and not actual turnover, which is reported to be higher than actual turnover rates [21]. In 2018, the annual average nurse turnover rate was 13.9\% in Korea [5].

We found that fatigue was common in our subjects, highly related to turnover intention, and had the highest odds ratio $(\mathrm{OR}=3.4,95 \% \mathrm{CI}=2.21-5.24)$. Our results were consistent with a previous study that reported a positive correlation between fatigue and turnover intention [39]. Although we could not determine with certainty how long they had suffered from fatigue, it appeared that fatigue was one of the common disabling health problems that lead to turnover intention. Fatigue may exert a direct effect on turnover intention since nurses' fatigue has been reported to interfere with work efficiency and concentration and increase the risk of medical error and injury $[40,41]$. Although the direction of causality was not identified, nurses' fatigue was reported to be related to sleep disturbance, poor health, and depression $[18,25]$.

Not surprisingly, we found that about $50 \%$ of nurses complained of fatigue and sleep disturbance at the same time and sleep disturbance was associated with turnover intention as a single health problem $(\mathrm{OR}=1.61,95 \% \mathrm{CI}=1.10-2.37)$. Sleep disturbance has received the most attention as a cause of turnover intention among nurses' health problems [42,43]. Irregular and insufficient sleep time due to shift work may often cause sleep disturbance, which may affect nurses' physical and mental health [1]. Another finding of interest was that about $28 \%$ of nurses had all three interrelated symptoms of fatigue, sleep disturbances, and depression; this was associated with turnover intention as a single health problem $(\mathrm{OR}=1.79,95 \% \mathrm{CI}=1.22-2.62)$. Depression in nurses is prevalent in many studies, and in one study, the prevalence of depression among nurses was almost twice as high as in other professions [26,44,45]. Depression may decrease concentration, which reduces the productivity of nursing and affects nurses' judgment, thus increasing occupational injury and turnover intention [26,43].

Our study revealed that fatigue, sleep disturbance, and depression may play important roles in increasing turnover intention as a cluster and as individual symptoms. Approximately one-third of nurses experienced all three health problems; these findings suggest fatigue, sleep disturbance, and depression in the neuropsychological cluster were correlated with each other. Despite the fact that biological and behavioral mechanisms in the development of depression, fatigue, and sleep disturbances are unknown, several studies have reported that these three health problems are related and co-occur [46,47]. Most importantly, $80 \%$ of nurses experienced one or more health problems in the neuropsychological cluster and this cluster was associated with turnover intention. Moreover, their odds ratio of turnover intention increased linearly as the number of health problems increased within this cluster. Future studies should probe the comorbidity of sleep disturbance, depression, and fatigue of shift work nurses and develop comprehensive health promotion to alleviate these three health problems.

We found that having a gastrointestinal disorder was another common health problem, which was consistent with the result of a previous study of 20,000 Korean nurses [12]. This high prevalence of gastrointestinal disorders among shift work nurses may, first, be due to disturbed circadian rhythm. The gastrointestinal system, like sleep, has a circadian rhythm, which controls bowel movement and the secretion of gastric juices [48]. Second, it might be due to irregular meal times and skipped meals [49]. Although not shown in the result, most of the nurses in our study reported eating irregularly $(92.8 \%)$ and they ate breakfast twice a week, which was lower than the average number of times Korean adults eat breakfast [50]. The most common reason for skipped meals in our study was irregular work times $(64.8 \%)$. Considering that having a gastrointestinal disorder was common among shift work nurses and was a single health problem that increased turnover intention, special attention needs to be paid to having regular and sufficient mealtimes as much as possible. 
In our results, gastrointestinal disorders and headaches formed the gastrointestinal cluster. This connection could be explained by the association between the brain and the stomach through neural, endocrine, and immune pathways and the high prevalence of headaches in patients with a gastrointestinal disorder [51,52]. However, the gastrointestinal cluster was not related to turnover intention. It is possible that headaches, as an individual health problem, had no significant association with turnover intention, which could have decreased the effect of the cluster. Furthermore, we presume that headaches as a single health problem were not shown to be associated with turnover intention because headaches are often easily relieved by medication and may not have been as severe as a gastrointestinal disorder.

Upper musculoskeletal pain, which had the highest prevalence, formed a pain cluster with leg or foot discomfort. Nurses work most of the time in a standing position, walking an average of 8747 steps (4.1 miles) per shift [53], and high physical demands have been associated with musculoskeletal problems in nurses [54]. Additionally, multi-site musculoskeletal pain has been shown to be more common than single-site pain, especially in women [55]. Unexpectedly, this cluster was not related to turnover intention, although leg or foot discomfort was related to turnover intention. This might be because most nurses (82\%) suffered upper musculoskeletal pain regardless of turnover intention and, similar to the gastrointestinal cluster, the association of the pain cluster with turnover intention was reduced by the effect of upper musculoskeletal pain. Although the pain cluster did not relate to turnover intention, given that these health problems in the pain cluster had a high prevalence and cause sickness and absence from work and decreased work productivity [24], there is a need to investigate the prevalence of musculoskeletal disorders in nurses by workplace and to provide appropriate prevention and treatment programs.

Although our study provides a new perspective on nurses' health problems, it has some limitations. First, this study relied on self-report measures of health problems, except for three health problems (sleep disturbance, depression, and fatigue). Second, we surveyed only the presence of health problems, but not the severity; however, as the participants were nurses with medical knowledge, their judgment of the presence of health problems might be more reliable than that of the general public [56], which would partially compensate for the fact that some health problems were not assessed with standardized tools. Third, we could not infer the causal relationship from the cross-sectional design of the study. The fourth significant limitation is that this study did not measure how many nurses actually leave their job; therefore, the findings of our study may not apply to actual turnover, as turnover intention does not always lead to actual turnover. Fifth, the shift work nurses who participated were all female and from two tertiary hospitals in Seoul in Korea. Therefore, the generalizability of the results is limited. Future studies on the comorbidity of sleep disturbance, depression, and fatigue in shift work nurses from various hospitals in various regions, along with the inclusion of male nurses, are recommended.

\section{Conclusions}

In this study, the association of single health problems and clusters of health problems with turnover intention differed. Although fatigue, sleep disturbance, depression, gastrointestinal disorders, and leg or foot discomfort were related to turnover intention as single health problems, after clustering, only the neuropsychological cluster-including fatigue, sleep disturbance, and depression-was related to turnover intention. Given that nurses had more than two health problems and turnover intention increased linearly within the neuropsychological cluster, these problems must receive close attention and be addressed to decrease the nurse turnover rate. Future studies should implement longitudinal research to determine the effect of the neuropsychological cluster on turnover.

Author Contributions: J.K. developed the concept of this manuscript, analyzed the data, and prepared this manuscript. J.R. and J.B. were responsible for the data collection and contributed to the manuscript revision. I.H. developed the study protocol and advised on the data analysis. S.C.-K. developed the study protocol and 
concept, and revised this manuscript to its final version. All authors have read and agreed to the published version of the manuscript.

Funding: This work was supported by the National Research Foundation of Korea (NRF) grant funded by the Korea Ministry of Science and ICT (No. NRF-2017R1A2B2002652).

Conflicts of Interest: The authors declare no conflict of interest.

\section{References}

1. Kecklund, G.; Axelsson, J. Health consequences of shift work and insufficient sleep. BMJ 2016, 355, i5210. [CrossRef] [PubMed]

2. Letvak, S. We cannot ignore nurses' health anymore: A synthesis of the literature on evidence-based strategies to improve nurse health. Nurs. Adm. Q. 2013, 37, 295-308. [CrossRef] [PubMed]

3. Hayward, D.; Bungay, V.; Wolff, A.C.; MacDonald, V. A qualitative study of experienced nurses' voluntary turnover: Learning from their perspectives. J. Clin. Nurs. 2016, 25, 1336-1345. [CrossRef]

4. Duffield, C.M.; Roche, M.A.; Homer, C.; Buchan, J.; Dimitrelis, S. A comparative review of nurse turnover rates and costs across countries. J. Adv. Nurs. 2014, 70, 2703-2712. [CrossRef]

5. Korea Hospital Nurse Association. Survey on the Status of Hospital Nursing Staffing; Korea Hospital Nurse Association: Seoul, Korea, 2018.

6. Yeom, E.Y.; Jeong, G.S.; Kim, K.A. Influencing Factors on Presenteeism of Clinical Nurses. Korean J. Occup. Health Nurs. 2015, 24, 302-312. [CrossRef]

7. Lee, Y.; Jung, M. Presenteeism and absenteeism according to health problems on nurses. J. Korean Acad. Community Health Nurs. 2008, 19, 459-468.

8. Yoshida, M.; Miki, A. Factors Related to Presenteeism in Young and Middle-aged Nurses. J. Occup. Health 2018, 60, 31-40. [CrossRef]

9. Yassi, A.; Lockhart, K. Work-relatedness of low back pain in nursing personnel: A systematic review. Int. J. Occup. Environ. Health 2013, 19, 223-244. [CrossRef]

10. Abdul Rahman, H.; Abdul-Mumin, K.; Naing, L. Psychosocial Work Stressors, Work Fatigue, and Musculoskeletal Disorders: Comparison between Emergency and Critical Care Nurses in Brunei Public Hospitals. Asian Nurs. Res. 2017, 11, 13-18. [CrossRef]

11. Wong, H.; Wong, M.C.S.; Wong, S.Y.S.; Lee, A. The association between shift duty and abnormal eating behavior among nurses working in a major hospital: A cross-sectional study. Int. J. Nurs. Stud. 2010, 47, 1021-1027. [CrossRef]

12. Kim, O.; Ahn, Y.; Lee, H.Y.; Jang, H.J.; Kim, S.; Lee, J.E.; Jung, H.; Cho, E.; Lim, J.Y.; Kim, M.J.; et al. The Korea Nurses' Health Study: A Prospective Cohort Study. J. Women's Health 2017, 26, 892-899. [CrossRef] [PubMed]

13. Zhai, L.; Zhang, H.; Zhang, D. Sleep Duration and Depression among Adults: A Meta-Analysis of Prospective Studies. Depress. Anxiety 2015, 32, 664-670. [CrossRef] [PubMed]

14. Caruso, C.C. Negative Impacts of Shiftwork and Long Work Hours. Rehabil. Nurs. 2014, 39, 16-25. [CrossRef] [PubMed]

15. Ferri, P.; Guadi, M.; Marcheselli, L.; Balduzzi, S.; Magnani, D.; Di Lorenzo, R. The impact of shift work on the psychological and physical health of nurses in a general hospital: A comparison between rotating night shifts and day shifts. Risk Manag. Healthc. Policy 2016, 9, 203-211. [CrossRef] [PubMed]

16. Kim, H.-J.; McGuire, D.B.; Tulman, L.; Barsevick, A.M. Symptom clusters: Concept analysis and clinical implications for cancer nursing. Cancer Nurs. 2005, 28, 270-282. [CrossRef]

17. Barsevick, A. Defining the Symptom Cluster: How Far Have We Come? Semin. Oncol. Nurs. 2016, 32, 334-350. [CrossRef]

18. Oyane, N.M.F.; Pallesen, S.; Moen, B.E.; Akerstedt, T.; Bjorvatn, B. Associations Between Night Work and Anxiety, Depression, Insomnia, Sleepiness and Fatigue in a Sample of Norwegian Nurses. PLoS ONE 2013, 8, e70228. [CrossRef]

19. Tuckett, A.; Henwood, T.; Oliffe, J.L.; Kolbe-Alexander, T.L.; Kim, J.R. A Comparative Study of Australian and New Zealand Male and Female Nurses' Health. Am. J. Men's Health 2016, 10, 450-458. [CrossRef]

20. Meeusen, V.C.; Van Dam, K.; Brown-Mahoney, C.; Van Zundert, A.A.; Knape, H.T. Understanding nurse anesthetists' intention to leave their job: How burnout and job satisfaction mediate the impact of personality and workplace characteristics. Health Care Manag. Rev. 2011, 36, 155-163. [CrossRef] 
21. Estryn-Behar, D.; van der Heijden, B.; Fry, C.; Hasselhorn, H. Longitudinal Analysis of Personal and Work-Related Factors Associated With Turnover Among Nurses. Nurs. Res. 2010, 59, 166-177. [CrossRef]

22. Han, K.; Trinkoff, A.M.; Gurses, A.P. Work-related factors, job satisfaction and intent to leave the current job among United States nurses. J. Clin. Nurs. 2015, 24, 3224-3232. [CrossRef] [PubMed]

23. Turpin, R.S.; Ozminkowski, R.J.; Sharda, C.E.; Collins, J.J.; Berger, M.L.; Billotti, G.M.; Baase, C.M.; Olson, M.J.; Nicholson, S. Reliability and validity of the Stanford Presenteeism Scale. J. Occup. Environ. Med. 2004, 46, 1123-1133. [CrossRef] [PubMed]

24. Stolt, M.; Suhonen, R.; Virolainen, P.; Leino-Kilpi, H. Lower extremity musculoskeletal disorders in nurses: A narrative literature review. Scand. J. Public Health 2016, 44, 106-115. [CrossRef]

25. Cai, S.; Lin, H.; Hu, X.; Cai, Y.; Chen, K.; Cai, W. High fatigue and its associations with health and work related factors among female medical personnel at 54 hospitals in Zhuhai, China. Psychol. Health Med. 2018, 23, 304-316. [CrossRef] [PubMed]

26. Brandford, A.A.; Reed, D.B. Depression in registered nurses: A state of the science. Workplace Health Saf. 2016, 64, 488-511. [CrossRef]

27. Kang, W.; Jang, K.-H.; Lim, H.-M.; Ahn, J.-S.; Park, W.-J. The menstrual cycle associated with insomnia in newly employed nurses performing shift work: A 12-month follow-up study. Int. Arch. Occup. Environ. Health 2019, 92, 227-235. [CrossRef]

28. Morin, C.M.; Belleville, G.; Bélanger, L.; Ivers, H. The Insomnia Severity Index: Psychometric indicators to detect insomnia cases and evaluate treatment response. Sleep 2011, 34, 601-608. [CrossRef]

29. Krupp, L.B.; LaRocca, N.G.; Muir-Nash, J.; Steinberg, A.D. The fatigue severity scale: Application to patients with multiple sclerosis and systemic lupus erythematosus. Arch. Neurol. 1989, 46, 1121-1123. [CrossRef]

30. Radloff, L.S. The CES-D Scale: A Self-Report Depression Scale for Research in the General Population. Appl. Psychol. Meas. 1977, 1, 385-401. [CrossRef]

31. Dunn, H.; Quinn, L.; Corbridge, S.J.; Eldeirawi, K.; Kapella, M.; Collins, E.G. Cluster analysis in nursing research: An introduction, historical perspective, and future directions. West. J. Nurs. Res. 2018, 40, 1658-1676. [CrossRef]

32. Clatworthy, J.; Buick, D.; Hankins, M.; Weinman, J.; Horne, R. The use and reporting of cluster analysis in health psychology: A review. Br. J. Health Psychol. 2005, 10, 329-358. [CrossRef] [PubMed]

33. Brooks, I.; Swailes, S. Analysis of the relationship between nurse influences over flexible working and commitment to nursing. J. Adv. Nurs. 2002, 38, 117-126. [CrossRef]

34. Milisen, K.; Abraham, I.; Siebens, K.; Darras, E.; Dierckx de Casterlé, B. Work environment and workforce problems: A cross-sectional questionnaire survey of hospital nurses in Belgium. Int. J. Nurs. Stud. 2006, 43, 745-754. [CrossRef] [PubMed]

35. Jiang, F.; Zhou, H.; Rakofsky, J.; Hu, L.; Liu, T.; Wu, S.; Liu, H.; Liu, Y.; Tang, Y. Intention to leave and associated factors among psychiatric nurses in China: A nationwide cross-sectional study. Int. J. Nurs. Stud. 2019, 94, 159-165. [CrossRef] [PubMed]

36. Camerino, D.; Conway, P.M.; Estryn-Béhar, M.; Costa, G.; Hasselhorn, H.-M. Age-dependent relationships between work ability, thinking of quitting the job, and actual leaving among Italian nurses: A longitudinal study. Int. J. Nurs. Stud. 2008, 45, 1645-1659. [CrossRef]

37. Estryn-Béhar, M.; Van der Heijden, B.I.; Ogińska, H.; Camerino, D.; Le Nézet, O.; Conway, P.M.; Fry, C.; Hasselhorn, H.-M. The impact of social work environment, teamwork characteristics, burnout, and personal factors upon intent to leave among European nurses. Med. Care 2007, 45, 939-950. [CrossRef] [PubMed]

38. Chang, C.S.; Du, P.L.; Huang, I.C. Nurses' perceptions of severe acute respiratory syndrome: Relationship between commitment and intention to leave nursing. J. Adv. Nurs. 2006, 54, 171-179. [CrossRef]

39. Liu, Y.; Wu, L.M.; Chou, P.L.; Chen, M.H.; Yang, L.C.; Hsu, H.T. The influence of work-related fatigue, work conditions, and personal characteristics on intent to leave among new nurses. J. Nurs. Scholarsh. 2016, 48, 66-73. [CrossRef]

40. Richter, K.; Acker, J.; Adam, S.; Niklewski, G. Prevention of fatigue and insomnia in shift workers-a review of non-pharmacological measures. EPMA J. 2016, 7, 16. [CrossRef]

41. Ferris, J. Nursing Fatigue: An Evidence-Based Practice Review for Oncology Nurses. Clin. J. Oncol. Nurs. 2015, 19, 662-664. [CrossRef] 
42. Shimizu, T.; Eto, R.; Horiguchi, I.; Obata, Y.; Feng, Q.; Nagata, S. Relationship between Turnover and Periodic Health Check-Up Data among Japanese Hospital Nurses: A Three-Year Follow-Up Study. J. Occup. Health 2005, 47, 327-333. [CrossRef] [PubMed]

43. Lai, H.; Lin, Y.; Chang, H.; Wang, S.; Liu, Y.; Lee, H.; Peng, T.; Chang, F. Intensive care unit staff nurses: Predicting factors for career decisions. J. Clin. Nurs. 2008, 17, 1886-1896. [CrossRef]

44. Hsieh, M.L.; Li, Y.M.; Chang, E.T.; Lai, H.L.; Wang, W.H.; Wang, S.C. Sleep disorder in Taiwanese nurses: A random sample survey. Nurs. Health Sci. 2011, 13, 468-474. [CrossRef] [PubMed]

45. Sun, Q.; Ji, X.; Zhou, W.; Liu, J. Sleep problems in shift nurses: A brief review and recommendations at both individual and institutional levels. J. Nurs. Manag. 2019, 27, 10-18. [CrossRef]

46. Bower, J.E.; Ganz, P.A.; Irwin, M.R.; Kwan, L.; Breen, E.C.; Cole, S.W. Inflammation and behavioral symptoms after breast cancer treatment: Do fatigue, depression, and sleep disturbance share a common underlying mechanism? J. Clin. Oncol. Off. J. Am. Soc. Clin. Oncol. 2011, 29, 3517-3522. [CrossRef]

47. Ho, S.-Y.; Rohan, K.J.; Parent, J.; Tager, F.A.; McKinley, P.S. A longitudinal study of depression, fatigue, and sleep disturbances as a symptom cluster in women with breast cancer. J. Pain Symptom Manag. 2015, 49, 707-715. [CrossRef]

48. Knutsson, A.; Bøggild, H. Gastrointestinal disorders among shift workers. Scand. J. Work. Environ. Health 2010, 36, 85-95. [CrossRef]

49. Joung Kim, Y.; Ban, D.J. Prevalence of irritable bowel syndrome, influence of lifestyle factors and bowel habits in Korean college students. Int. J. Nurs. Stud. 2005, 42, 247-254. [CrossRef]

50. Cho, S.H.; Chun, H.; Lee, H.S.; Lee, S.W.; Shim, K.W.; Lee, J.Y.; Byun, A.R.; Lee, H.Y. The Relationship between Shared Breakfast and Skipping Breakfast with Depression and General Health State in Korean Adults: The 2014 Korea National Health and Nutrition Examination Survey. Korean J. Fam. Pract. 2018, 8, 441-447. [CrossRef]

51. Lee, S.; Lee, J.; Kwon, Y.; Kim, J.; Sohn, J. Clinical Implications of Associations between Headache and Gastrointestinal Disorders: A Study Using the Hallym Smart Clinical Data Warehouse. Front. Neurol. 2017, 8, 526. [CrossRef]

52. Aamodt, A.; Stovner, L.; Hagen, K.; Zwart, J. Comorbidity of Headache and Gastrointestinal Complaints. The Head-HUNT Study. Cephalalgia 2008, 28, 144-151. [PubMed]

53. Welton, J.M.; Decker, M.; Adam, J.; Zone-Smith, L. How far do nurses walk? Medsurg Nurs. 2006, 15, $213-216$. [PubMed]

54. Trinkoff, A.M.; Lipscomb, J.A.; Geiger-Brown, J.; Storr, C.L.; Brady, B.A. Perceived physical demands and reported musculoskeletal problems in registered nurses. Am. J. Prev. Med. 2003, 24, 270-275. [CrossRef]

55. Carnes, D.; Parsons, S.; Ashby, D.; Breen, A.; Foster, N.; Pincus, T.; Vogel, S.; Underwood, M. Chronic musculoskeletal pain rarely presents in a single body site: Results from a UK population study. Rheumatology 2007, 46, 1168-1170. [CrossRef]

56. Colditz, G.A.; Hankinson, S.E. The Nurses' Health Study: Lifestyle and health among women. Nat. Rev. Cancer 2005, 5, 388-396. [CrossRef]

(C) 2020 by the authors. Licensee MDPI, Basel, Switzerland. This article is an open access article distributed under the terms and conditions of the Creative Commons Attribution (CC BY) license (http://creativecommons.org/licenses/by/4.0/). 